\title{
The identification of abrasive grains in the decohesion process by acoustic emission signal patterns
}

\author{
Pawel Sutowski $^{1} \cdot$ Krzysztof Nadolny $^{1}$
}

Received: 10 October 2015 / Accepted: 9 February 2016 / Published online: 23 February 2016

(C) The Author(s) 2016. This article is published with open access at Springerlink.com

\begin{abstract}
The article presents the results of basic research focused on the decohesion phenomenon characteristics of selected abrasive grains using acoustic emission signal patterns. On the basis of the recorded signals, their detailed analysis in the time-frequency domain and their characteristic harmonic components were selected. The method developed for estimating the similarity of the harmonic sequences will be further used in a comparative analysis with the degree of similarity of acoustic emission signal patterns to determine the type of grain in the decohesion process inducted by an external force or stress field. The proposed technique of grain recognition can be used in grinding wheel wear diagnostic systems, especially in cases where it is significant for supervision or inspection of cracking and chipping abrasive grain vertices.
\end{abstract}

Keywords Abrasive grains · Brittle fracture - Acoustic emission · Identification $\cdot$ Signal analysis

\section{Nomenclature}

AE Acoustic emission

CZT The chirp $\mathbb{Z}$ transform

DTFT Discrete Time Fourier Transform

FFT Fast Fourier transform

GCD The greatest common divisor

Krzysztof Nadolny

krzysztof.nadolny@tu.koszalin.pl

Paweł Sutowski

pawel.sutowski@tu.koszalin.pl

1 Department of Production Engineering, Faculty of Mechanical Engineering, Koszalin University of Technology, Racławicka 15-17, 75-620 Koszalin, Poland
PSD The power spectrum density

A Starting point for the logarithmic spiral

$A E_{\text {raw }} \quad$ Filtered raw acoustic emission signal, V

$c \quad$ Length of crack, mm

$d_{y} \quad$ Size of the deformation zone (aka: process-zone), $\mathrm{mm}$

E Young's modulus, $\mathrm{Pa}$

$f \quad$ Frequency, $\mathrm{Hz}$

$f_{0} \quad$ Fundamental frequency of signal, $\mathrm{Hz}$

$f_{\text {norm }} \quad$ Normalized frequency, $\pi \cdot$ radian/sample

$f_{m} \quad$ Frequency of the $m$ th harmonic component, $\mathrm{Hz}$

$f_{s} \quad$ Sampling frequency of signal, $\mathrm{Hz}$

$G_{c} \quad$ Material toughness, $\mathrm{kJ} / \mathrm{m}^{2}$

$i \quad$ The imaginary unit (for complex number)

$j \quad$ Index number

$k \quad$ Time lag (shifting of the signal), samples

$K \quad$ Overlapping length of segments (in Welch's method), samples

$K_{1 c} \quad$ Fracture toughness, $\mathrm{MPa} \cdot \mathrm{m}^{1 / 2}$

$l \quad$ The point number on the logarithmic spiral (in chirp $\mathbb{Z}$-transform)

$m \quad$ Natural number, greater than 1

$M \quad$ Length of window function (in Welch's method) or length of the transform, samples

$n \quad$ Signal's sample number

$N \quad$ Signal's number of samples

$P \quad$ Power of signal

$R_{c} \quad$ Compressive strength, $\mathrm{Pa}$

$R_{m} \quad$ Tensile strength, $\mathrm{Pa}$

$R_{x x} \quad$ Autocorrelation scalar

$R_{x y} \quad$ Cross-correlation scalar

$S \quad$ Number of signal's segments (in Welch's method)

$s_{c} \quad$ Shape coefficient

$t \quad$ Time, $\mathrm{s}$

$T_{0} \quad$ Fundamental period of signal, $\mathrm{s}$ 
$t_{s} \quad$ Time of signal sampling, $\mathrm{s}$

$T_{S} \quad$ Sampling interval, second per sample

$w \quad$ Window function (in Welch's method)

$W \quad$ Index representing the distance between the logarithmic spiral contour points

$x \quad$ The $x$ signal, $\mathrm{V}$

$X \quad$ Fourier's transform of signal $x$

$y \quad$ The $y$ signal, $\mathrm{V}$

$Y \quad$ Fourier's transform of signal $y$

$y^{*} \quad$ Composite conjugation of the $y$ signal sample, $\mathrm{V}$

$\hat{y} \quad$ Segments of signal multiplied by the window function (in Welch's method)

$\hat{Y} \quad$ Fourier's transform of signal's segments $\hat{y}$ (in Welch's method)

$z_{l} \quad$ The $l$ point from a section of the logarithmic spiral (in chirp $\mathbb{Z}$-transform)

$\Theta \quad$ The shift determining the bottom frequency in analysis (angle in chirp $\mathbb{Z}$-transform)

$\nu \quad$ Poisson's ratio

$\sigma_{c} \quad$ Brittle material cracking stress value, $\mathrm{Pa}$

$\sigma_{f} \quad$ Strength, resistance to compression/stretching, or the yield point, $\mathrm{Pa}$

$\varphi \quad$ Phase angle, radians

$\phi \quad$ The inverse of the magnification ratio (angle in chirp $\mathbb{Z}$-transform)

$\omega_{0}$

Fundamental pulsatance (angular frequency) of signal, radians per second

\section{Introduction}

Expanding our knowledge concerning basic phenomena in grinding processes occur mainly through research and analyses of the process of microcutting with a single microblade in the so-called scratch test. The elementary phenomena that accompany the materials microcutting process influence the course of this process, its energy-consumption, microgeometry, and condition of the workpiece surface layer, as well as the wear of the cutting blade (abrasive grain) [1, 2]. What is, however, registered when using the latest solutions in the field of monitoring and diagnosing such processes (including analysis of the acoustic emission signal), are signals from the tool, the workpiece, and the work station devices [3]. In order to separate the signals that come only from the abrasive grains, an attempt at analyzing the phenomenon of decohesion of grains in the single-axis compression method was made in the research work undertaken. On the one hand, the applied method of grain static loading only partially corresponds to the real conditions of the grain cracking processes in the dynamic process of contact of the active cutting apexes with the workpiece surface. However, on the other hand, it makes it possible to analyze the signals that come from only one source (the cracking abrasive grains), having eliminated many additional signals, allowing for precise identification of the elementary phenomena of the examined process.

\section{Brittle cracking of abrasive grains}

Abrasive grains that have been the subject of research are ceramic materials which are part of the non-metal engineering materials characterized in numerous works on materials science [4-6]. According to these works, alumina oxides have considerable hardness and resultant high wear resistance, but limited strength, while silicon carbide is characterized by high-temperature strength and wear resistance. Hardness, on the other hand, is the feature that may be referred to the measure of resistance to brittle cracking.

Ceramic materials' fragility results mainly from the nature of bonds and their microstructural construction [5]. Resistance to cracking may be interpreted as the material's tolerance to microstructure discontinuities or the presence of defects in the form of already existing microcracks. Fragility, as a physical feature that characterizes a given material, may be interpreted as the relation of resistance to stretching $R m$ and the resistance to compression $R c$, with which the crushing occurs. In the case of ceramic materials, of which the examined abrasive grains are a part, this relation is $1: 15$ [7].

Brittle cracking is connected with so-called material toughness $\left(G_{c}\right)$. This determines the material's resistance to cracking that corresponds to the energy consumed when the crack that destroys the material occurs. Resistance to brittle cracking is determined with the value of the fracture toughness $\left(K_{I c}\right)[7]$ :

$G_{c}=\frac{K_{I c}^{2}}{E(1+\nu)}, \mathrm{kJ} / \mathrm{m}^{2}$,

$K_{I c}=Y \sigma_{c} \sqrt{\pi c}, \mathrm{MN} / \mathrm{m}^{1 / 2}\left(=\mathrm{MPa} \cdot \mathrm{m}^{1 / 2}\right)$,

where: $Y$ - shape coefficient (close to a unit, dependent on the geometric shape), $E$-Young's module, $\nu$-Poisson's number, $\sigma_{c}$-stress at which the brittle material cracking begins, with a crack of $2 \times c$ length.

Both groups of analyzed materials (aluminum oxides and silicon carbides) have a similar material resistance to cracking: $G_{c}=0.05 \mathrm{~kJ} / \mathrm{m}^{2}, K_{I c}=2-5 \mathrm{MPa} \cdot \mathrm{m}^{1 / 2}[7]$.

The chart illustrating the fracture toughness as compared against the specific strength of various groups of materials (Fig. 1), points to the tendency of an increase in resistance to brittle cracking and the material strength.

In the grinding process, microcutting occurs through the contact of the abrasive grain active apex with the machined material. The concentration of stress around the active apex causes the creation of a zone (a zone of micro-cracking in ceramics) in which friction forces and resistance occur, and 
Fig. 1 The fracture toughness in comparison with the strength of various groups of materials [7]

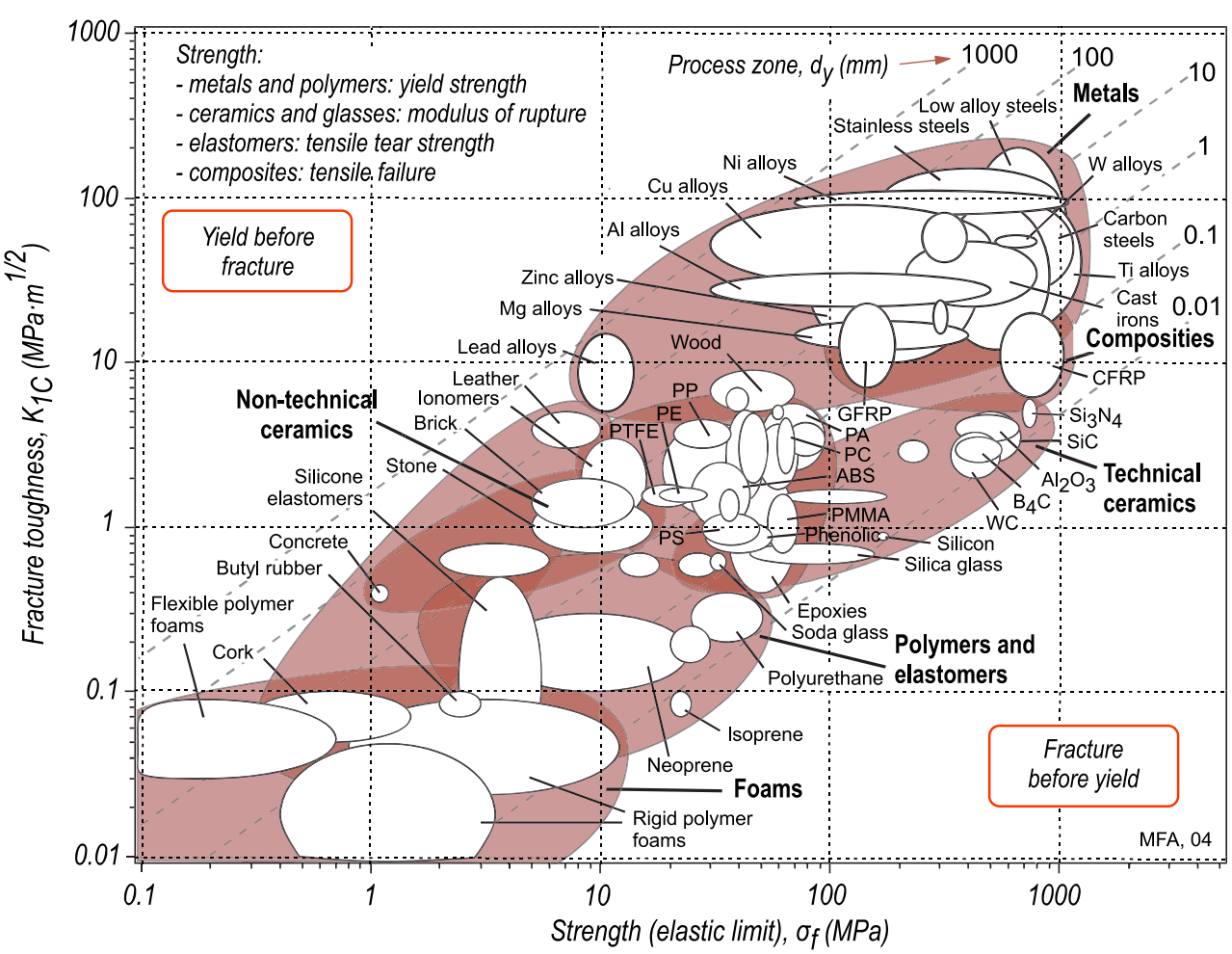

as a result, microcracks. The amount of scattered energy depends on the size of the deformation zone (aka: the processzone) $d_{y}[7]$ :

$d_{y}=\frac{K_{I c}^{2}}{\pi \sigma_{f}^{2}}, \mathrm{~mm}$,

where: $\sigma_{f}$-resistance to compression/stretching or the yield point (MPa).

The size of the deformation zone (dashed lines on the chart, Fig. 1) ranges widely from $0.0001 \mathrm{~mm}$ (for very brittle materials) to $100 \mathrm{~mm}$ (for plastic metals). The analysis of Fig. 1 clearly shows that the examined abrasive grains are materials resistant to compression but also very brittle.

Similar properties of abrasive materials, especially the relatively small differences in values of the characteristic parameters such as the stress intensity coefficient and resistance to compression, make differentiating the grains using analysis of the brittle cracking process a difficult task.

Registration of the stress waves, generated by the cracks and microcracks, requires developing a special method, strictly oriented at identifying the phenomena characteristic of a given abrasive grain type.

\section{Abrasive grains identification methodology}

The experimental plan included four different types of abrasive grains. Out of the large number of abrasive grains on the market, the most popular were selected: White fused alumina (99A), green silicon carbide (99C), and microcrystalline sol-gel sintered alumina $\left(\mathrm{SG}^{\mathrm{TM}}\right)$. Aluminium oxynitride grains $(\mathrm{AlON})$, under the trade name $A b r a l \circledast$, were included into the study as new generation grains, due to the characteristics of the material.

In previous studies, we presented the view that the presence of aluminum nitride in AlON grains affects their significantly higher hardness at high temperatures, in comparison with the most common grains based on $\mathrm{Al}_{2} \mathrm{O}_{3}[8,9]$. The content of aluminum nitride also prevents the surface of these grains being wetted by molten steel. This results in the possibility of reducing the phenomenon of the adhesion of the workpiece to the active abrasive grain vertices and contributes to reducing the intensity of the clogging formations on the active surface of the grinding wheel [10-15].

All of the abrasive grains tested were made from ceramic materials and have No. 46, determined by the FEPA standard (FEPA standard 42-1: 2006) for sizes in the range of $325-400 \mu \mathrm{m}$. The values of selected grain parameters used in experimental studies are presented in Table 1.

Samples of the abrasive grains were tested for resistance to a slowly increasing load by static axial compression. As a result of the load of the samples, the tension was increased. Upon reaching the level destructive compression $(R c)$, the resultant catastrophic damage of the grain was observed.

The experimental tests were carried out on a work stand for resistance tests, equipped with a type $\mathrm{W}$ horizontal testing Tensometer, made by the Monsanto Company (Great Britain). This device worked together with measurement 
Table 1 The properties of the abrasive grains types analyzed during experiments [16-19]

\begin{tabular}{|c|c|c|c|c|}
\hline & White fused alumina $99 \mathrm{~A}$ & Microcrystalline sintered corundum & Silicon carbide 99C & Abral ${ }^{\circledR}$ \\
\hline Full name & Fused alumina $\mathrm{Al}_{2} \mathrm{O}_{3}$ & $\begin{array}{l}\text { Microcrystalline sol-gel sintered } \\
\text { alumina }\end{array}$ & $\begin{array}{l}\text { Silicon carbide green } \\
\text { SiCg }\end{array}$ & Aluminium oxynitride $\mathrm{Al}_{x} \mathrm{O}_{y} \mathrm{~N}_{z}$ \\
\hline Shape & Pointed, sharp & Pointed, very sharp & Sharp, angular & Pointed, very sharp \\
\hline Specific density & $3.96 \mathrm{~g} / \mathrm{cm}^{3}$ & $3.87 \mathrm{~g} / \mathrm{cm}^{3}$ & $3.12-3.21 \mathrm{~g} / \mathrm{cm}^{3}$ & $3.65 \mathrm{~g} / \mathrm{cm}^{3}$ \\
\hline Knoop hardness HK & $20.3 \mathrm{GPa}$ & $21.5 \mathrm{GPa}$ & $24-30 \mathrm{GPa}$ & $18.0 \mathrm{GPa}$ \\
\hline Ductility & $2.0 \mathrm{MPa} \cdot \mathrm{m}^{1 / 2}$ & $3.7 \mathrm{MPa} \cdot \mathrm{m}^{1 / 2}$ & $2.2-3.3 \mathrm{MPa} \cdot \mathrm{m}^{1 / 2}$ & $1.65 \mathrm{MPa} \cdot \mathrm{m}^{1 / 2}$ \\
\hline $\begin{array}{l}\text { The critical stress intensity } \\
\text { factor } K_{I c}\end{array}$ & $2.7 \mathrm{MPa} \cdot \mathrm{m}^{1 / 2}$ & $3.5-4.3 \mathrm{MPa} \cdot \mathrm{m}^{1 / 2}$ & $1.9 \mathrm{MPa} \cdot \mathrm{m}^{1 / 2}$ & - \\
\hline $\begin{array}{l}\text { Coefficient of friction } \\
\text { (hardened steel) }\end{array}$ & 0.34 & 0.19 & - & - \\
\hline $\begin{array}{l}\text { Thermal conductivity } \\
\text { coefficient } \lambda\end{array}$ & $27-35 \mathrm{~W} / \mathrm{m} \cdot \mathrm{K}$ & $27-35 \mathrm{~W} / \mathrm{m} \cdot \mathrm{K}$ & $42.5 \mathrm{~W} / \mathrm{m} \cdot \mathrm{K}$ & - \\
\hline
\end{tabular}

components made by Hottinger Baldwin Messtechnik GmbH (Germany), which included a two-channel MP85A measurement amplifier, as well as force and track sensors. There were also parts of the measurement track mounted on the stand for registering the acoustic emission signal (AE) that came from the direct proximity of the compression zone.

The most important element of the system for registering the AE signal was a type $8152 \mathrm{~B} 211$ piezoelectric sensor, made by the Kistler Instrument Corporation (Switzerland). This device worked in conjunction with a type PXIe-1073 system of data acquisition, made by the National Instruments Corporation (USA). In order to interpret the obtained measurements correctly, observation of grains before and after the decohesion process was carried out using a JSM-5500LV electron scanning microscope, manufactured by JEOL Ltd. (Japan).

The test conditions for the abrasive grain decohesion process are presented in Table 2.

Discerning the type of grain that undergoes catastrophic destruction is difficult as all of the examined grains belong to the ceramic materials group whose nature is similar to that of brittle cracking. The signal analysis methodology required the application of multistep acoustic emission (AE) processing.

The developed methodology of acoustic emission analysis is composed of a few phases. The initial phase of analysis

Table 2 Test conditions for abrasive grain decohesion process

\begin{tabular}{ll}
\hline Parameter & Condition \\
\hline Avg. test speed & $1.2 \mathrm{~mm} / \mathrm{min}$ \\
Load cell range & Up to $20 \mathrm{kN}$ \\
Displacement measuring accuracy & $0.001 \mathrm{~mm}$ \\
Force sensor measuring accuracy & $0.006 \mathrm{kN}$ \\
Sampling frequency & $2.5 \mathrm{MHz}$ \\
Digitizing & 16 bit \\
Filter & Band-pass: $50-1000 \mathrm{kHz}$ \\
\hline
\end{tabular}

consisted of preparing the signal for further research. As a result of data acquisition, band-pass filtering, locating position, and extracting signal regions of interest, a record of signal pulses was obtained reflecting the grain cracking events. These signals were aligned with other samples using crosscorrelation $[20,21]$ :

$R_{x y}(k)=\frac{1}{N} \sum_{n=0}^{N-1} x(n) y^{*}(n-k)$,

where: $R_{x y}$-scalar product of two signals in the function of shifting of one of them, $k$-shifting of the signal (time lag), $n$-signal sample number, $x()$ - value of the $x$ signal, $y^{*}()-$ composite conjugation of the $y$ signal sample, $N$-number of samples.

The basic part of the tests was divided into two stages. Characteristics in the field of time and frequency were determined in the first stage. For each sample the amplitude of signal in time domain was analyzed. In the second step, the amplitude and phase spectra, spectrogram (signal amplitude spectrum for each time moment $t$ ) and fundamental frequency of signal were determined. The second part of the analysis was searching through the whole frequency band in order to determine the harmonic sequences characteristic of a given abrasive grain type. The research was completed with the creation of unique and unambiguous patterns for the identification process.

Due to the form of the recorded AE signals - a pulse with finite total energy - the most appropriate tool for their analysis was the use of power spectrum density (PSD), which describes the frequency distribution of signal energy [22, 23]:

$P=\sum_{n=0}^{N-1}|x(n)|^{2}=\frac{1}{N} \sum_{k=0}^{N-1}|X(k)|^{2}$,

where: $|X(k)|^{2}$ measures the power of the signal at frequency of $f_{k}, X(k)$ is the Discrete Time Fourier Transform (DTFT) from $x(n)$ signal; both arrays have a length of $N$. 
The spectral density function was estimated using Welch's non-parametric method. This consists of dividing the signal into overlapping segments, multiplying these segments by the window function and calculating the fast Fourier transform (FFT) on the modified data. Finally, the spectrum module square is averaged and normalized (Fig. 2) [24, 25].

The fundamental component of the composite sinusoidal signal is a harmonic wave, usually one of lower frequency in a harmonic sequence. This frequency is usually marked with index $0\left(f_{0}\right)$ [20]. All of the remaining signal components are the multiple of the fundamental frequency, whereby the fundamental component might be defined as the greatest common divisor (GCD) of the other greater harmonic components of the signal [26]:

$f_{0}=1 / T_{0}=\omega_{0} / 2 \pi \equiv \operatorname{GCD}\left(f_{1}, f_{2}, \ldots, f_{n}\right)$,

$f_{n}=f_{0} \cdot n$,

where: $f_{0}$ - fundamental frequency, $T_{0}$-fundamental period, $\omega_{0}$-fundamental pulsatance (angular frequency), $f_{n}$ frequency of the $n$th harmonic component, $n-$ natural number, greater than 1 .

Although the harmonic components might have any amplitude, this usually decreases as the frequency increases (Fig. 3) [20].

The number and amplitude of the greater components have a decisive influence on the timbre of a sound. They create an individual signal spectrum which makes it possible to differentiate between various sources, even with the same sound pitch (fundamental frequency). The timbre of a given source can be changed depending on $[20,26,27]$ :

- the way the vibrations are triggered (dynamics of triggering the center's elastic wave),

- the excitation force,

- the frequency,

- changes in time (sound envelope).

Therefore, it may be assumed that the fundamental frequency and other components of our knowledge of the acoustic emission signal spectrum, will allow for their unambiguous identification of abrasive grains in their decohesion process.

The autocorrelation method may be used in order to determine the fundamental frequency, as it is often used in measuring signal parameters when noise or random interference occurs [28-31]. A correlation between two signals is a measure of their similarity. The courses of these signals are compared in the function of time delays while their "identity" is calculated in each range. What is examined in the case of autocorrelation function is the correlation between subsequent values (observations) of the same wave $f$. Autocorrelation can be calculated between the 1st and 2nd following observations (signal sample) and between the 1st and 3rd following observations or between the 1st and 4th observations and so on. The number of omissions of subsequent observations is called the time lag $(k)$.
Fig. 2 A graphic interpretation of the power spectral density calculation with the use of Welch's method (own work based on $[24,25])$

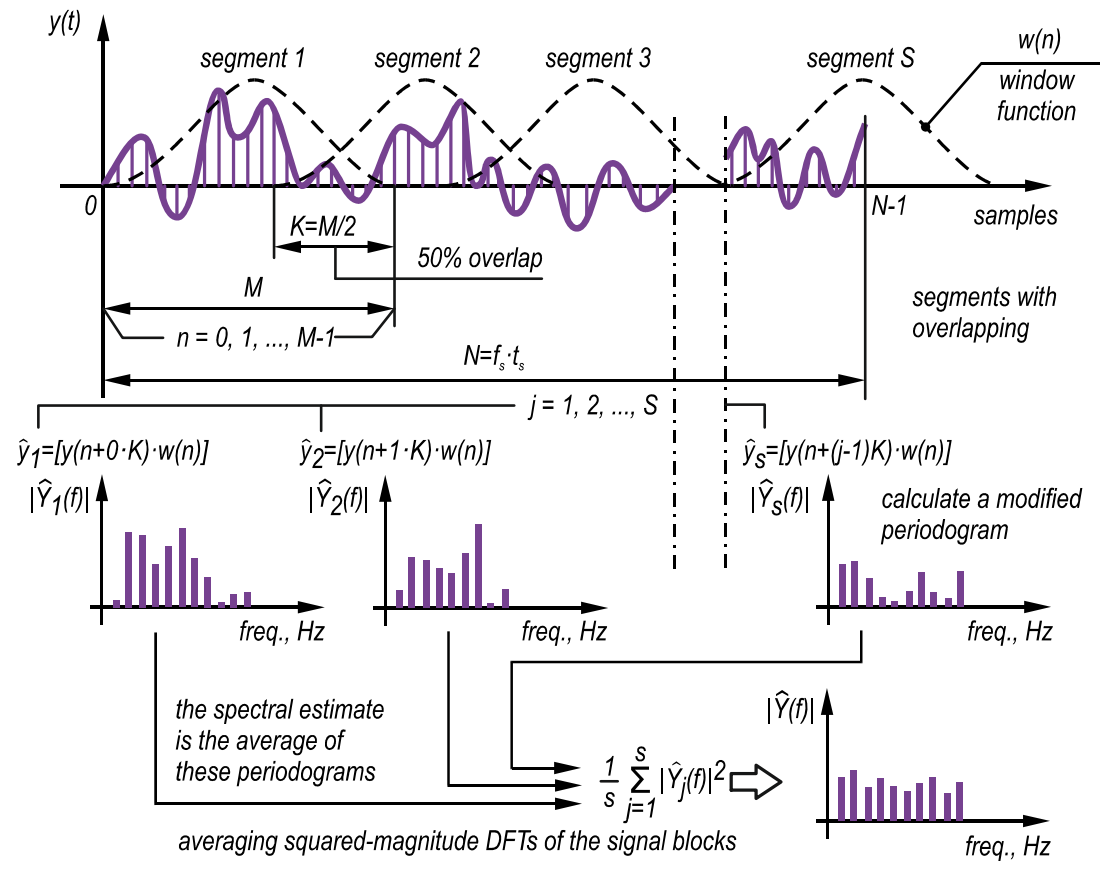


Fig. 3 An example of a harmonic in a signal: a a symmetrically distorted signal, $\mathbf{b}$ fundamental frequency and other harmonics [20]

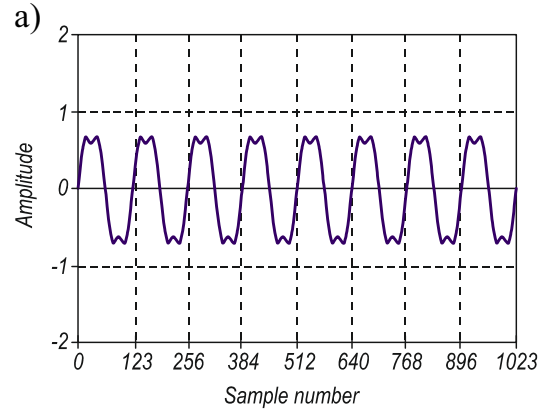

The function of the discrete signal autocorrelation is a periodic function with the same period as the signal and may be expressed with the following dependence [21, 23]:

$R_{x x}(k)=\left\{\begin{array}{cc}\frac{1}{N-k} \sum_{n=0}^{N-k-1} x(n+k) x(n) & k \geq 0 \\ R_{x x}(-k) & k<0\end{array}\right.$.

Graphic representations of signal autocorrelation are presented using graphs called autocorrelograms (Fig. 4).

By definition, the tone of a sound (corresponding to its fundamental component) may be determined on the basis of the location of a maximum autocorrelation function (in other words: in the time lag/autocorrelation/domain), while the harmonics-to-noise ratio may be determined on the basis of the relative volume of its maximum [27].

In order to more accurately perform a spectrum analysis of recorded signals, the chirp $\mathbb{Z}$-transform (CZT) algorithm was used. This makes it possible to "enlarge" the spectrum in a narrow frequency band $\left(f_{1}-f_{2}\right)$. The chirp $\mathbb{Z}$-transform, unlike the Fourier transform that operates on a unit circumference, calculates the spectrum for points from a section of the logarithmic spiral (Fig. 5a) [20, 35-38]:

$z_{k}=A W^{-k}$ for $k=0, \ldots, M-1$,

where: $M$-the length of the transform, $A$-starting point for the curve described on plane $\mathbb{Z}$ of complex coordinates,
$W$ - the index representing the distance between the spiral contour points, $k$ - the point number on the logarithmic spiral.

Parameters $A$ and $W$ influence the transform's modification. Parameter $W$ is strictly connected with angle $\Phi$, which operates like the inverse of the magnification ratio- the smaller the $\Phi$, the greater the magnification. The second parameter is connected with additional rotation of the input signal. Angle $\Theta$ is treated as a shift in the frequency determining the bottom analysis border $\left(f_{1}\right)$ [38]:

$W=e^{-j 2 \pi \phi / k}, \phi \equiv \Delta f=f_{2}-f_{1}$,

$A=e^{-j 2 \pi \Theta n / k}$.

Using properties of the exponential functions, the complex variable function is substituted with a simpler form (Fig. 5b) [38]:

$x\left(z_{k}\right)=W^{k^{2} / 2} \sum_{n=0}^{N-1} x(n) A^{-n} W^{n^{2} / z} W^{-(k-n)^{2} / 2}$.

In the cases of $A=1, M=N$, and $W=\mathrm{e}^{(-\mathrm{j} 2 \pi / N)}$ a direct connection with the discrete Fourier transform is obtained [20,38]:

$z_{k}=1 \cdot\left(e^{-j 2 \pi / N}\right)^{-k}=e^{j 2 \pi k / N}$

Fig. 4 Sample plots with autocorrelation function (autocorrelograms) for: a sinusoidal signal (free from noise), $\mathbf{b}$ sinusoidal signal of a random signal, $\mathbf{c}$ narrowband random signal, and $\mathbf{d}$ wideband random signal [32-34] a)

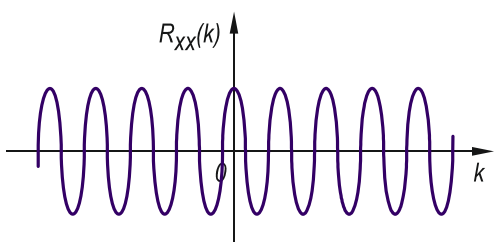

c)

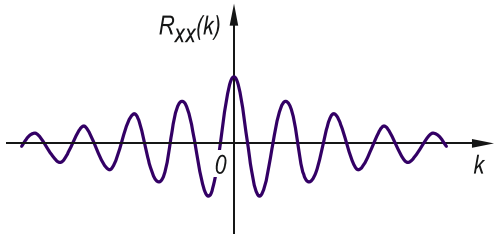

b)

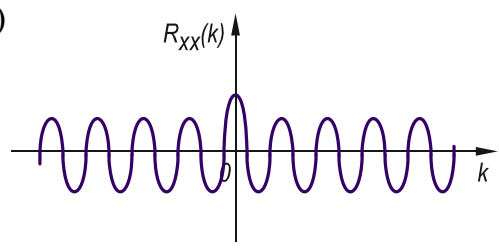

d)

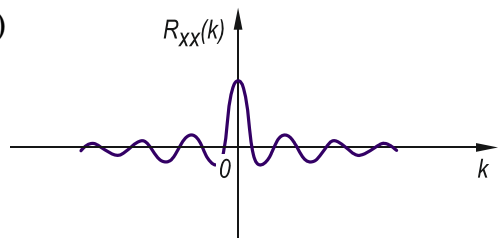


a)

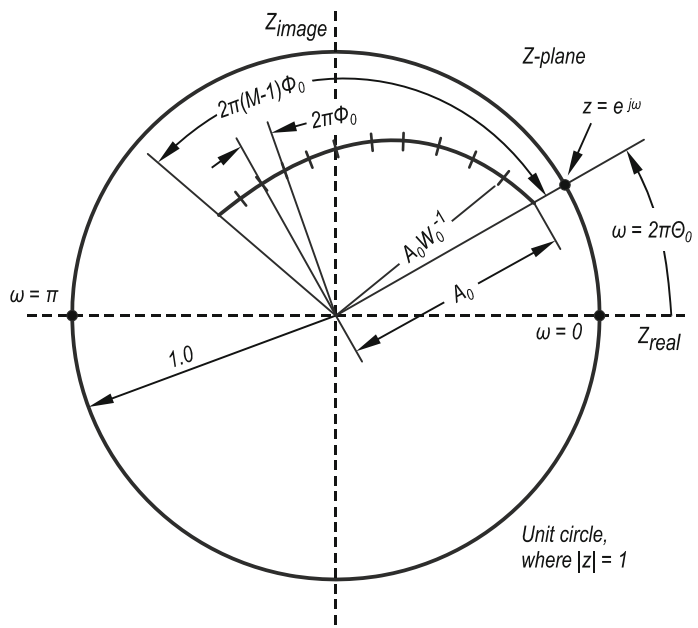

b)

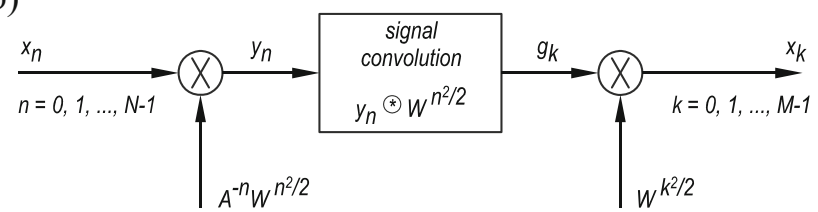

Fig. 5 An illustration of chirp $\mathbb{Z}$-transform: a transform parameters and b a block diagram of the spectral determining procedure [38]

$X\left(z_{k}\right)=\sum_{n=0}^{N-1} x(n) z_{k}^{-n}$.

Because of this, determining the signal spectrum with the chirp $\mathbb{Z}$-transform method is considered to be more effective than direct application of the Fourier transform [20, 38].

\section{Research results and their analysis}

The applied piezoelectric acoustic emission sensor is characterized by very high sensitivity to surface (Rayleigh) waves and longitudinal waves in a wide frequency range from 100 to $900 \mathrm{kHz}$ (producer's data). The AE impulses were registered during experimental tests with a sampling frequency of $f_{s}=2.5 \mathrm{MHz}$. These waves were transformed by the measurement system into electric impulses with a voltage proportional to the energy source (system exCitation source). A converter, type 5125B (Kistler, USA) with filters of HPF $50 \mathrm{kHz}$ and LPF $1000 \mathrm{kHz}$, was used in the measurement system. Signals were acquired with a 16 bit converter A/C PXIe-6124 (National Instruments Corp., USA).

\subsection{Analyses in the time and frequency domain}

Registered signals possess the nature of exponentially damped impulses (Fig. 6). The source of each impulse is sudden and releases a large amount of energy that triggers vibrations of the

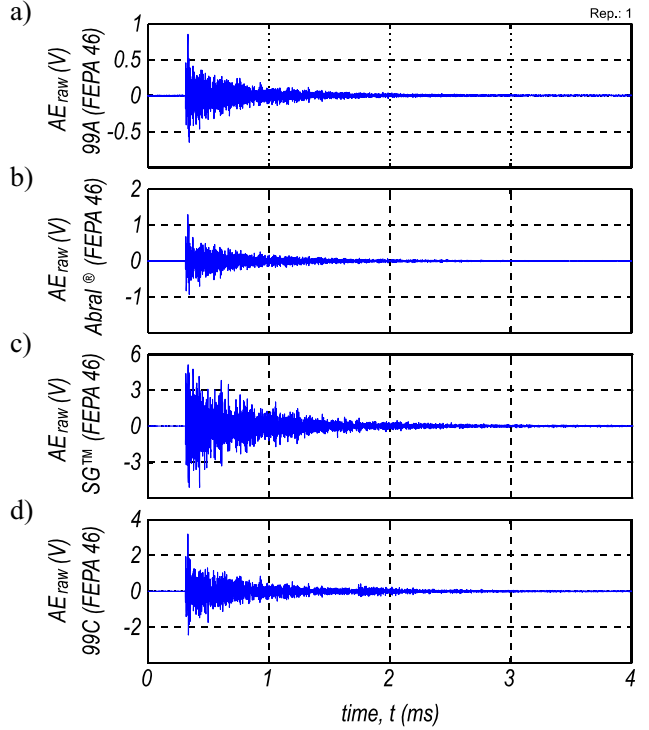

Fig. 6 Example impulses of an acoustic emission raw signal $\left(A E_{\text {raw }}\right)$ registered during breakage of abrasive grains for: a white fused alumina grain $(99 \mathrm{~A}), \mathbf{b}$ aluminium oxynitride grain (Abral $\left.{ }^{\circledR}\right), \mathbf{c}$ microcrystalline sintered corundum grain $\left(\mathrm{SG}^{\mathrm{TM}}\right)$, and $\mathbf{d}$ green silicon carbide grain $(99 \mathrm{C})$

acoustic wave propagation center. Thus, the bigger the amplitude of these impulses, the greater the energy created during grain cracking. After the sudden energy release, the stress waves are damped and scattered in their propagation center. A detailed analysis of these signals in the time domain is presented by the authors in the article [9].

The greatest fracture energy (manifested by the highest amplitude of the AE pulse) was characterized by a grain sample of SG ${ }^{\mathrm{TM}}$ and 99C (Fig. 6c-d). The smallest voltage on the piezoelectric transducer was produced during the cracking of grain type 99A (Fig. 6a).

The amplitude and phase frequency spectra of the acoustic signals of the cracking of grains subjected to static load show a common similarity (Fig. 7). The amplitude spectrums are presented in the form of a Fourier transform (Fig. 7a-d) and periodgrams (Fig. 7e) for which values of the harmonics on the axis of abscissa of the chart are recorded after normalization:

$f_{\text {norm }}=\frac{f_{\mathrm{Hz}} 2 \pi}{F_{s}}, f_{\mathrm{Hz}}=\frac{f_{\text {norm }} F_{s}}{2 \pi}$.

This results from the application of digital-signal processing (DSP), in which the natural time unit is the sample. The time continuous variable ( $t$, unit: second) is substituted with the discrete total variable ( $n$, unit: sample number). Time change (in seconds) undergoes normalization (division) by the sampling interval ( $T_{\mathrm{s}}$, unit: second per sample). Correspondingly, the natural frequency unit in DSP is the number of cycles/sample, radians/sample, or $\pi \cdot$ radians/ sample. The frequency expressed in these units is described 
Fig. 7 Comparison of acoustic emission signals in the frequency domain for: a white fused alumina grain (99A), b aluminum oxynitride grain (Abral®), c microcrystalline sintered corundum grain $\left(\mathrm{SG}^{\mathrm{TM}}\right)$, $\mathbf{d}$ green silicon carbide grain (99C), e power spectral density estimated by Welch's method (window length - 128 , length of overlapping segments - 64), and f phase spectrum of signals
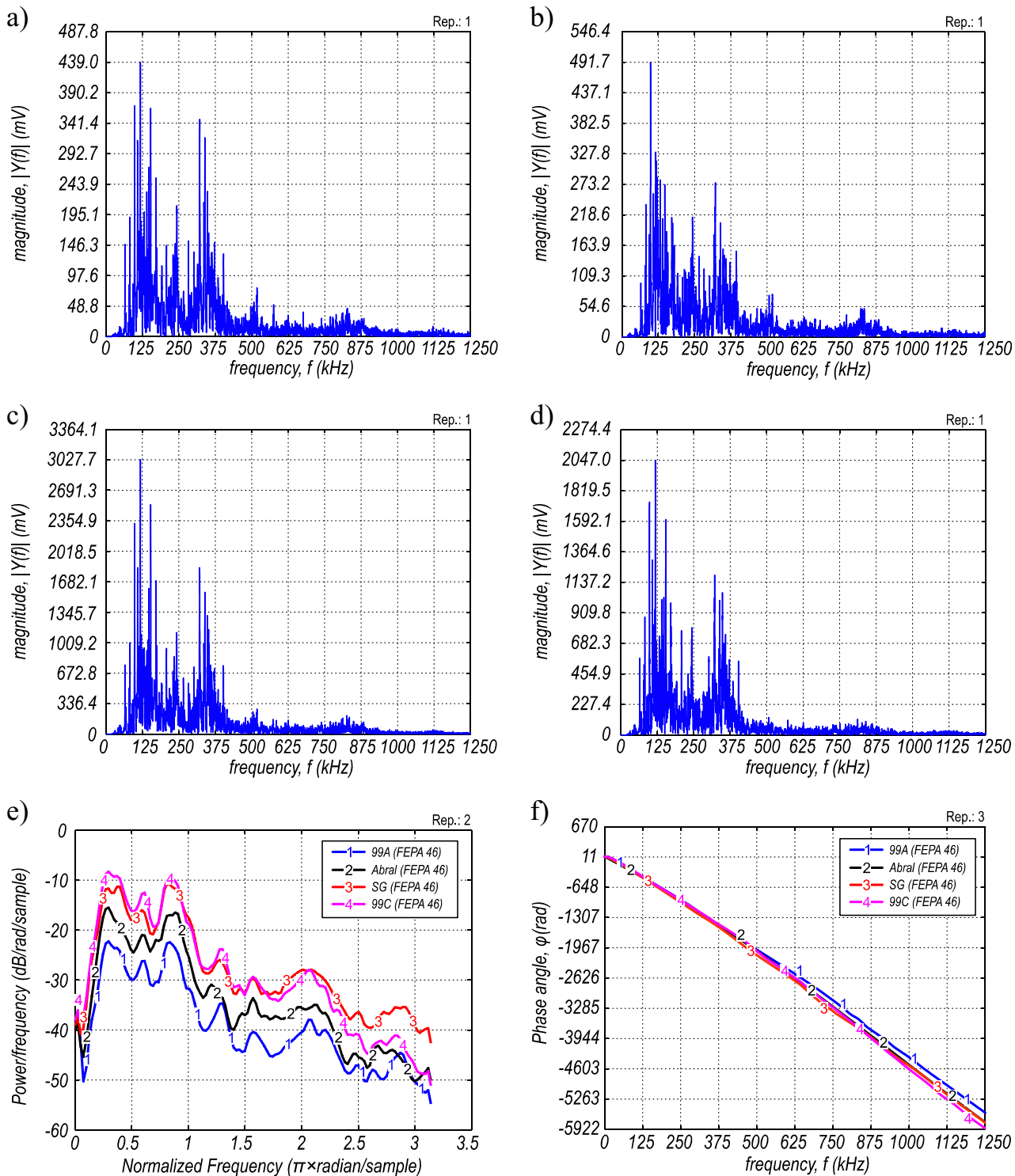

as normalized. The exemplary commutations of frequency between the absolute real value, expressed in hertz $\left(f_{\mathrm{Hz}}\right)$, and the normalized value expressed in $\pi \cdot$ radians/sample $\left(f_{\text {norm }}\right)$ are presented in Table 3.

The linear AE signal phase spectrum (Fig. 7f) clearly indicates that the individual components of this phase shifts proportional to the frequency. Negative values indicate that each subsequent sample (in the time domain) is shifted in a positive direction (to the right), which makes the phase (in the frequency domain) decreased by $\pi$ rad for each sample shift.
Regardless of the abrasive grain structure, the share of the frequency components in registered $\mathrm{AE}$ signals is similar. A clear difference occurs in the absolute value (magnitude) of intensity of particular harmonic components, dividing the analyzed grains into two groups: grains cracking with great energy (microcrystalline sintered corundum, green silicon carbide) and grains with an almost five-times lower energy (polycrystalline fused aluminum oxide, aluminum nitride-oxide). This is due to the difference in the hardness of the various types of abrasive grains (e.g., for microcrystalline sintered
Table 3 Examples of frequency conversion between absolute real and normalized values

\begin{tabular}{lllllllll}
\hline Variable & Unit & Value & & & & & \\
\hline $\mathrm{f}_{\text {norm }}$ & $\pi \cdot$ radians/sample & 0.5 & 1 & 1.5 & 2 & 2.5 & 3 & 3.5 \\
$f_{H z}$ & $\mathrm{kHz}$ & 198.94 & 397.88 & 596.83 & 795.77 & 994.71 & 1193.66 & 1392.6 \\
\hline
\end{tabular}


corundum grains, this is determined at the level of 24-30 GPa on the Knoop hardness scale), as well as from differences in the structural construction of mono-, poly-, and microcrystalline grains.

The obtained amplitude spectrum charts are characteristic of bottom-band signals for which the spectral concentration drops to zero as the pulsation increases to infinity. Therefore, in the averaged analysis, realized for the whole signal, a clear domination of low frequencies of 50 $500 \mathrm{kHz}(0.12-1.25 \pi \cdot \mathrm{radians} / \mathrm{sample})$ is visible. The greatest intensity is that of the harmonic components ranging from 100 to $400 \mathrm{kHz}(0.25-1.005 \pi$-radians/sample). In this range the majority of components comprise 120 (0.3 $\pi \cdot$ radians/sample), $240(0.6 \pi \cdot$ radians/sample $)$, and $350 \mathrm{kHz}(0.88 \pi \cdot$ radians/sample $)$.

The estimated spectral density function is calculated using Welch's non-parametric method, which represents the averaged signal spectrum (from the whole sample) of the acoustic emission. However spectrograms (Fig. 8) reveal that as time goes by, grain cracking $\mathrm{AE}$ signals are characterized by the disappearance of subsequent frequencies.

Damping of the medium in which the AE pulse propagates, results in a decrease in the wave amplitude over time, due to energy dissipation. The damping center can be classified as low (where the damping factor is in the range of $0<\zeta<1$ ), as the recorded oscillations are characterized by an exponentially decreasing amplitude (Fig. 6) and a reduction in the frequency

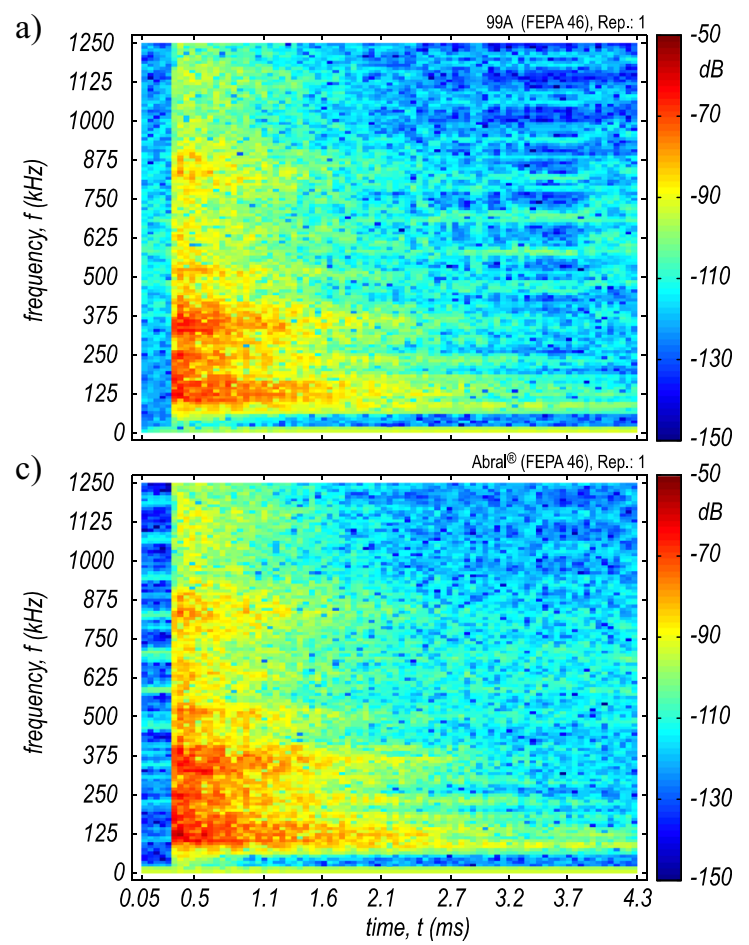

Fig. 8 Example spectrograms of analyzed signals (window typeHamming, window size -256 samples, overlap of segments-50\%) for grain cracking of: a white fused alumina grain (99A), b aluminum of vibration of the object concerned (Fig. 8). Spectrograms of acoustic emissions reveal that, with the passage of time, impulses possess fading high frequencies. Finally, the spectrum displays only extremely low frequency harmonics, which is characteristic of damped signals. Components are damped at different speeds, inversely in proportion to frequency. After 1$2 \mu \mathrm{s}$ high frequencies (over $1000 \mathrm{kHz}$ ) are damped, this occurs after $2-3 \mu$ s with medium frequencies $(500-875 \mathrm{kHz})$. Low frequencies (do $375 \mathrm{kHz}$ ) are characterized by highest amplitude and occur the longest after the signal. After $2 \mu \mathrm{s}$ their energy is damped by $-90 \mathrm{~dB}$ or less.

Figure 9 represents exemplary results of the examined autocorrelation analysis of acoustic emission signal samples. The location of the first local autocorrelation function maximum (for an argument other than zero) estimates the signal period expressed in samples. In order to determine the value of the fundamental harmonic component in $\mathrm{Hz}$, a conversion was performed by dividing the signal frequency $\left(F_{s}\right)$ by the number of the indicated sample (time lag, $k$ ).

The conducted analyses showed that the examined abrasive grains are characterized by very close values of the basic frequency of acoustic emission impulses registered in their cracking process (the values and results of the statistical analysis are presented in Table 4). The only registered acoustic emission signals were those with the fundamental component of $113 \mathrm{kHz}$ ( $58.3 \%$ of cases), $119 \mathrm{kHz}$ ( $25 \%$ of cases), or $166 \mathrm{kHz}(16.7 \%$ of cases).

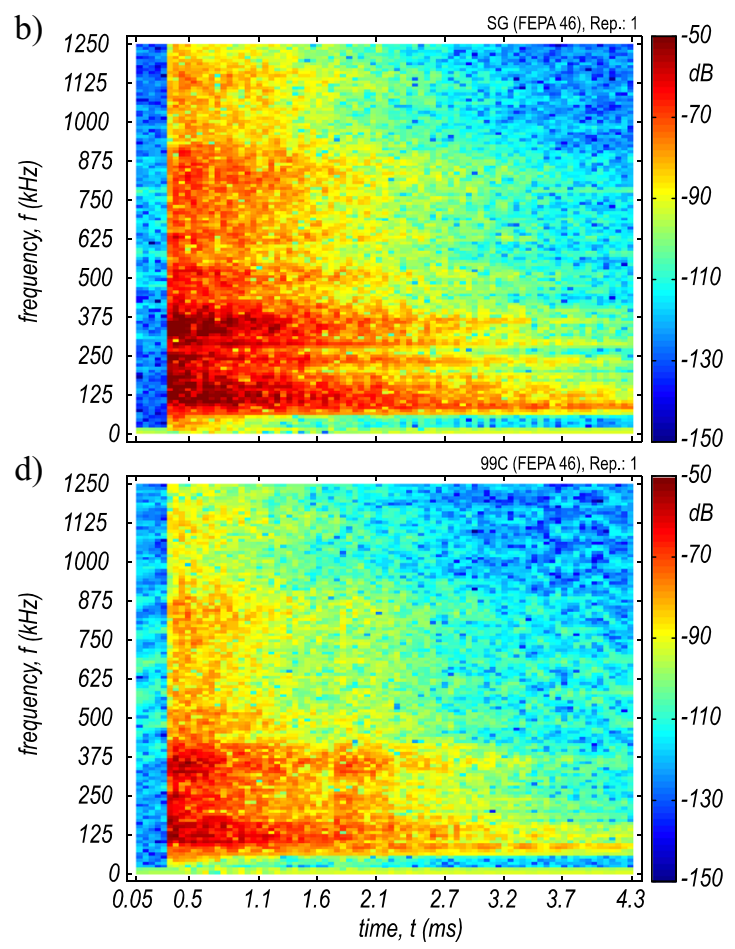

oxynitride grain $\left(\right.$ Abral $\left.{ }^{\circledR}\right)$, $\mathbf{c}$ microcrystalline sintered corundum grain $\left(\mathrm{SG}^{\mathrm{TM}}\right)$, and $\mathbf{d}$ green silicon carbide grain $(99 \mathrm{C})$ 
Fig. 9 The results of the fundamental frequency detection in AE signal with the use of autocorrelation analysis for: a white fused alumina grain (99A), b aluminum oxynitride grain (Abral®), c microcrystalline sintered corundum grain $\left(\mathrm{SG}^{\mathrm{TM}}\right)$, and $\mathbf{d}$ green silicon carbide grain (99C)
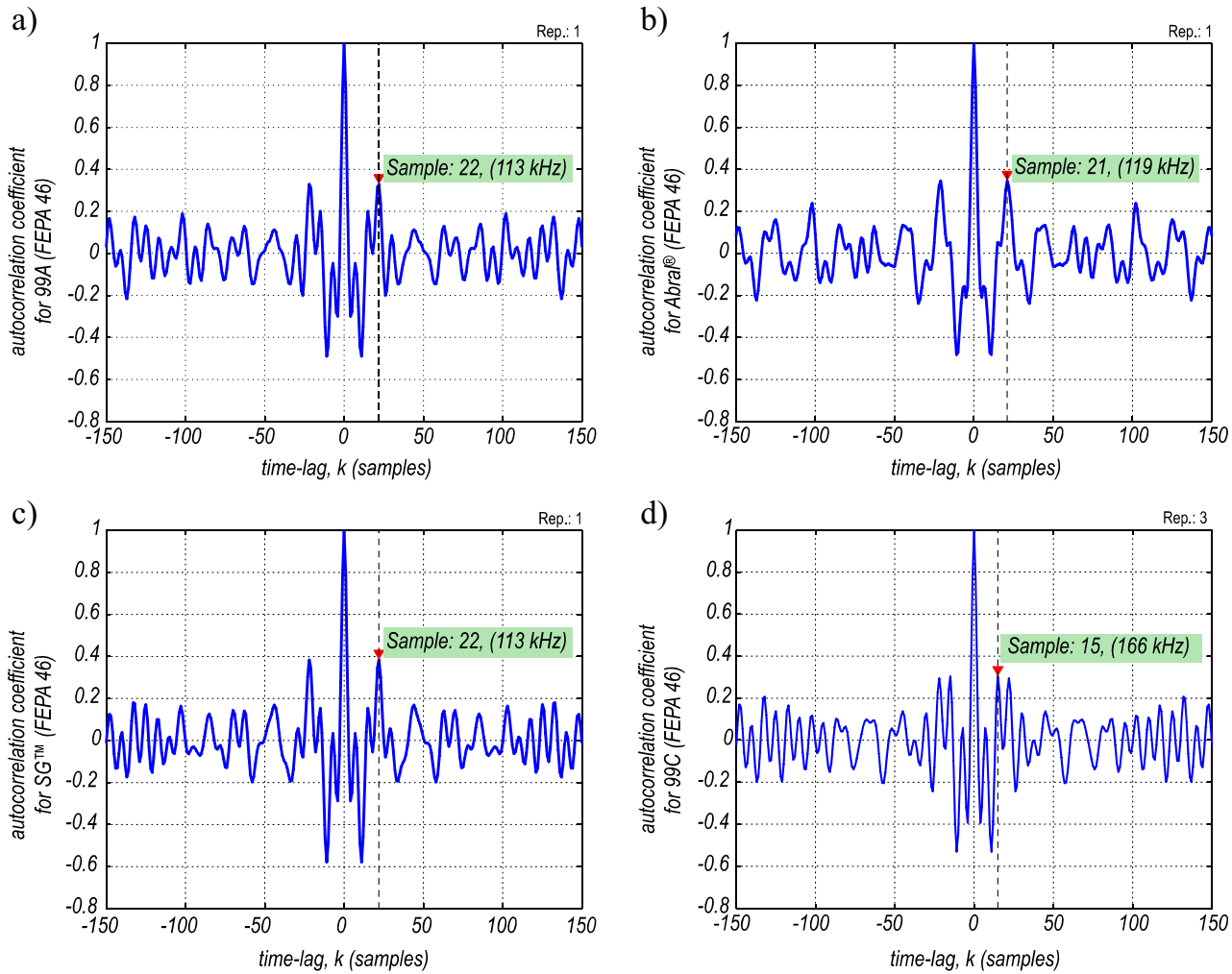

For each of the analyzed grains at least one case was registered in which the fundamental frequency was determined at a level of $113 \mathrm{kHz}$. For this reason, it may be concluded that it is an incident of typical harmonics which describes the abrasive grains decohesion phenomenon and also characterizes the damped elastic wave (center vibrations) transformed by the converter into the acoustic emission impulse by the measurement system.

The most stable basic frequency value, from among the analyzed signal samples, was observed for the cracking of polycrystalline fused aluminum oxide (99A) grains. In this case, a value of $113 \mathrm{kHz}$ was registered to each repetition of the experimental tests, which translated into a zero standard deviation and a lack of value distribution skewness. The relatively small range of basic frequency values $(6 \mathrm{kHz})$ and of its standard deviation $(3.5 \mathrm{kHz})$ was noted for aluminum nitride-oxide grain (Abral $\left.{ }^{\circledR}\right)$. The modal value for this grain was $119 \mathrm{kHz}$. Moreover, a left-sided value distribution asymmetry (negative skewness) shows that most results are above average value $(117 \mathrm{kHz})$, which is very close to the modal value. The enumerated features may be used as an identifier (discriminant) of such grains. These features can be used as an identifier of this grain type.

In the case of $\mathrm{SG}^{\mathrm{TM}}$ and $99 \mathrm{C}$ grains, we dealt with a relatively large basic frequency range $(53 \mathrm{kHz})$, which influenced the high value, both the average (of approximately $130 \mathrm{kHz}$ ) and the standard deviation (approximately $30 \mathrm{kHz}$ ). A right-sided distribution asymmetry shows that most of the obtained results are below the average value (approximately $130 \mathrm{kHz}$ ). With single samples it would be a very difficult task to discern between both
Table 4 Selected statistical parameters of fundamental frequency of acoustic emission impulses generated and recorded during a grain's decohesion process

\begin{tabular}{|c|c|c|c|c|c|c|c|}
\hline \multirow{2}{*}{$\begin{array}{l}\text { Grain } \\
\text { type }\end{array}$} & \multirow[t]{2}{*}{ Mean } & \multirow{2}{*}{$\begin{array}{l}\text { Standard } \\
\text { deviation }\end{array}$} & \multicolumn{2}{|c|}{$95 \%$ CI of mean } & \multirow[t]{2}{*}{ Skewness } & \multirow[t]{2}{*}{ Mode } & \multirow[t]{2}{*}{ Range (maximum - minimum) } \\
\hline & & & Lower & Upper & & & \\
\hline $99 \mathrm{~A}$ & 113 & 0 & 113 & 113 & - & 113 & 0 \\
\hline Abral ${ }^{\circledR}$ & 117 & 3.46 & 108.39 & 125.6 & -1.73 & 119 & 6 \\
\hline $\mathrm{SG}^{\mathrm{TM}}$ & 130.67 & 30.59 & 54.65 & 206.68 & +1.73 & 113 & 53 \\
\hline $99 \mathrm{C}$ & 132.67 & 29.02 & 60.56 & 204.76 & +1.64 & - & 53 \\
\hline
\end{tabular}


types of grains only on the basis of determination of the acoustic emission signal's fundamental frequency.

Although the above-mentioned results point to the possibility of applying analysis of basic frequency for grain identification, because of the high similarity of material properties of the described abrasive grains brittle cracking phenomenon, analysis may be considerably hindered and the results uncertain.

\subsection{Frequency signal patterns}

In order to determine patterns of the $\mathrm{AE}$ impulses destined for identifying various types of abrasive grains in their decohesion process, detailed acoustic emission signal decomposition in the frequency domain was used.

The methodology of finding specific signal components included selecting those frequencies for which the magnitude value was $60 \%$ or more of the maximum value. This included the selection of AE signal harmonic components that were found in the process of cracking of the given abrasive grain and whose power was greater than the signal background for the subsequent ranges of the whole spectrum. An analysis of this, and the characteristic frequency indications, was performed by dividing the full acoustic emission spectrum $(1-1250 \mathrm{kHz})$ into narrow bands whose width was 50, 40, 20 , or $10 \mathrm{kHz}$, depending on the concentration of harmonics that met the amplitude height condition.

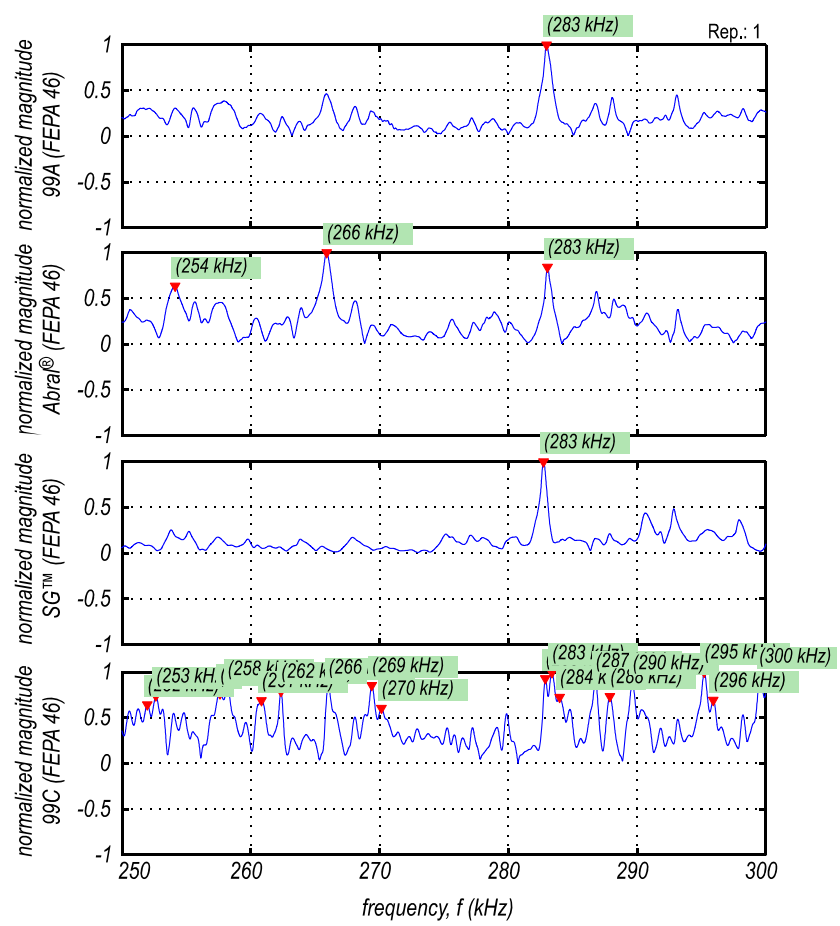

Fig. 10 Example harmonics of acoustic emission impulses in a narrow range of frequencies (250-300 KHz) using the chirp $\mathbb{Z}$ transformselected components exceed a yield of $60 \%$ of the normalized value
Figure 10 presents the magnified amplitude spectrum ranging $250-300 \mathrm{kHz}$. In this case, in the band $50 \mathrm{kHz}$ wide, the greatest number of components (around 18 positions) was singled-out for the 99C grain with far fewer, namely only three, for the Abral ${ }^{\circledR}$ grain. Single harmonics were indicated in the case of the remaining analyzed materials $-99 \mathrm{~A}$ and $\mathrm{SG}^{\mathrm{TM}}$.

Further research results proved that the described method is not maintained for each analyzed AE signal amplitude spectrum band section. The number of the characteristic harmonic components clearly depends on the analyzed frequency range, and to a smaller extent, on the abrasive grain type. In the general view of the full AE signal spectrum $(0-1250 \mathrm{kHz})$, the greatest number of selected harmonics was observed for the microcrystalline sintered corundum grains ( $\left.\mathrm{SG}^{\mathrm{TM}}\right)$, and the lowest for those of polycrystalline fused aluminum oxide (99A).

Figure 11 presents a sequence of frequencies characteristic of the cracking process with a division into the examined abrasive grain types. Against the black background there are markers corresponding to a specific frequency (with a resolution of up to $1 \mathrm{kHz}$ ). This example concerns a single experimental test attempt. The analysis of the presented standards points to an uneven (for the given grain) and inconsistent (various grains) distribution of the selected acoustic emission harmonic components in the process of the brittle cracking of abrasive grains.

Despite the clear differences, many of the components of a given frequency were selected from the signal simultaneously in the case of tests on two or more kinds of abrasive grains. In order to avoid inconsistency in the process of identifying the grain that undergoes decohesion, the standard construction algorithm separated for further analyses subgroups of the representative harmonic components - which occurred only in cases of a given abrasive grain. The thus-selected AE signal components differentiate a given grain's cracking process against other cases.

In order for the developed acoustic emission impulse patterns to be used in the monitoring process and in abrasive grain identification, spaces of all the alternative solutions (subsequent signal samples registered in the experimental tests repetitions) were sought in order to select signal harmonics appropriate for a given grain type.

A graphic representation of the abrasive grain decohesion acoustic emission impulse patterns (Fig. 12) indicates only those frequencies that occur in the signal regardless of the number of repetitions of the experimental test. Moreover, what was marked over the sequence of the singled-out frequencies were unique harmonics (arrows in Fig. 12), which, as might be suspected, are likely to characterize the process of cracking of a given abrasive grain type. Their occurrence in the AE signal spectrum is closely connected with a given grain type, along with its structure, mainly a microstructure created as a result of the technological production process. 
Fig. 11 A graphic representation of the acoustic emission signal components having an amplitude above the maximum value of 0.6 , including unique harmonics (shown in yellow) in the case of a single repetition of abrasive grain-decohesion test

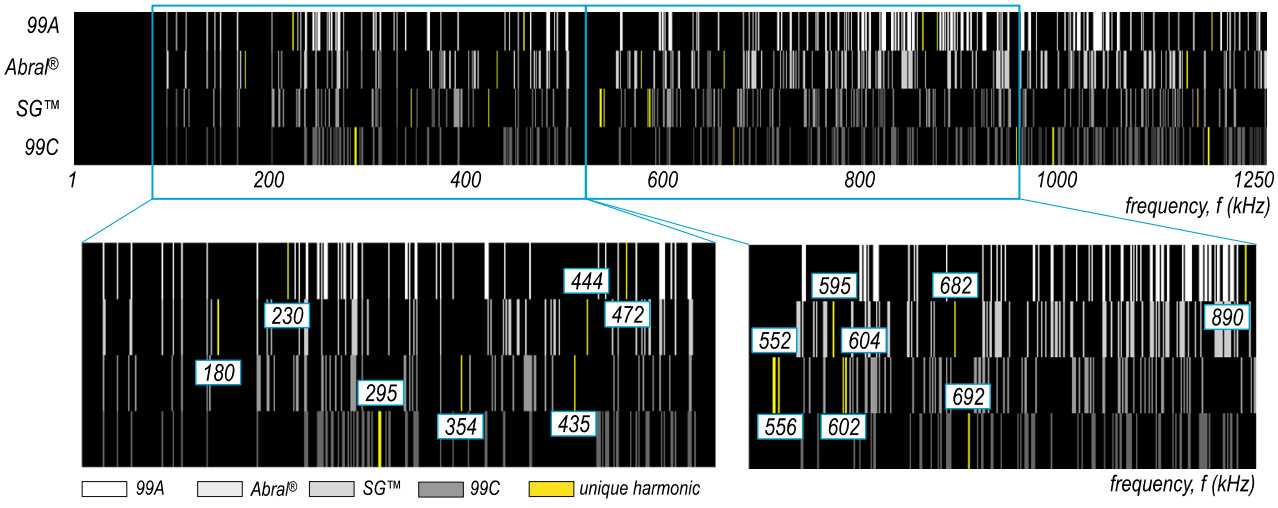

Assuming the acoustic emission signal spectrum creates a record of unique harmonic sequences, it can be compared against a previously prepared pattern (pattern sequence). One of the techniques that makes it possible to find the optimum global match for two sequences is the Needleman-Wunsch algorithm [39]. This is often used in bioinformatics as one of the tools for finding the linearity of nucleotide or amino-acid sequences [40, 41]. This algorithm, based on dynamic programming, can be easily adapted to the application being discussed.

Global matching, involving the full range of all sequences, is most useful when the compared sequences are similar and of approximate size (having a common origin) [39]. This condition will be met if the acoustic emission signal undergoes acquisition with the same frequency as the pattern sequence. As a result of the algorithm's operation, the quality of the sequence matching may be determined through the identity coefficient [39]. The high value of this coefficient proves that the sequence similarity is statistically high (is not incidental), and the potential mismatches may be interpreted as point mutations. However, the practical application of the
Needleman-Wunsch algorithm in order to compare acoustic emission signals requires detailed research and optimization work.

\section{Conclusions}

Brittle catastrophic abrasive grain cracking, caused by mechanical load, is the source of the stress waves which may be registered in the form of acoustic emission impulses. These impulses can be extracted from raw signals and analyzed by digital signal processing.

The above-presented test results show that determining the differences between the mechanical properties of ceramic materials, of which the analyzed abrasive grains are a part, is possible using static methods and only an acoustic emission signal. Analysis of the signal harmonic components makes it possible to determine patterns corresponding to the unique features of particular abrasive grain types.

The suggested patterns can be used in the systems of monitoring and diagnosing processes for which supervision of
Fig. 12 Graphical representation of the acoustic emission patterns with a mark of a very unique sequence of harmonics in signals (taking into account all experimental replicates)

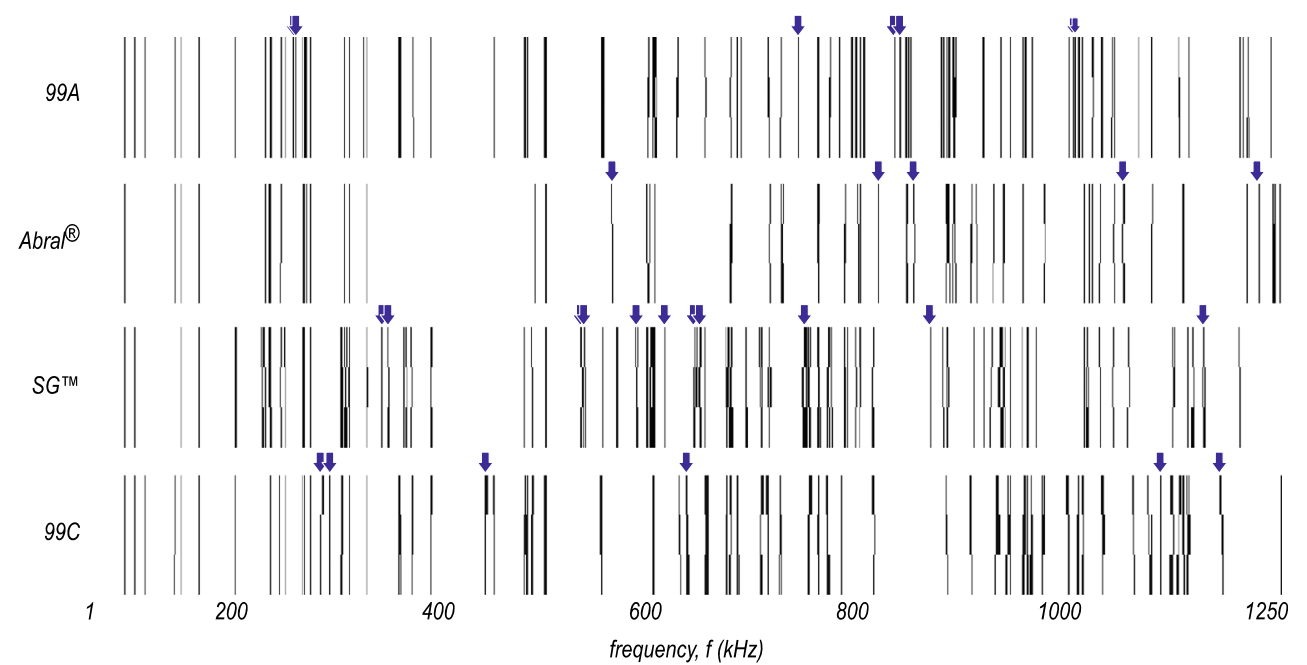


cracking and chipping of the abrasive grain active vertexes are considered to be crucial. This task can be carried out after the development of database templates and an efficient sequence comparison algorithm.

\section{Compliance with ethical standards}

Funding This study did not receive any grant funding.

Conflict of interest The authors declare that they have no conflict of interest.

Open Access This article is distributed under the terms of the Creative Commons Attribution 4.0 International License (http:// creativecommons.org/licenses/by/4.0/), which permits unrestricted use, distribution, and reproduction in any medium, provided you give appropriate credit to the original author(s) and the source, provide a link to the Creative Commons license, and indicate if changes were made.

\section{References}

1. Marinescu ID, Rowe WB, Dimitrov B, Inasaki I (2004) Tribology of abrasive machining processes. William Andrew, Norwich

2. Xu X, Yu Y, Huang H (2003) Mechanisms of abrasive wear in the grinding of titanium (TC4) and nickel (K417) alloys. Wear 255(712):1421-1426

3. Sutowski P, Nadolny K, Kapłonek W (2012) Monitoring of cylindrical grinding processes by use of a non-contact AE system. Int J Precis Eng Manuf 13(10):1737-1743. doi:10.1007/s12541-0120228-7

4. Bhargava AK (2005) Engineering materials: polymers, ceramics and composites. Prentice-Hall of India Pvt. Ltd, ISBN-13: 9788120325838

5. Richerson DW (2005) Modern ceramic engineering: properties, processing, and use in design. CRC Press, 3rd edition. ISBN: 978-1574446937

6. Newell JA (2008) Essentials of modern materials science and engineering. Wiley. ISBN: 978-0471753650

7. Ashby MF (2010) Materials selection in mechanical design. Butterworth-Heinemann, 4th edition. ISBN: 978-1856176637

8. Nadolny K (2014) State of the art in production, properties and applications of the microcrystalline sintered corundum abrasive grains. Int J Adv Manuf Technol 74(9):1445-1457. doi:10.1007/ s00170-014-6090-2

9. Nadolny K, Sutowski P, Herman D (2015) Analysis of aluminum oxynitride $\mathrm{AlON}\left(\mathrm{Abral}{ }^{\circledR}\right)$ abrasive grains during the brittle fracture process using stress-wave emission techniques. Int J Adv Manuf Technol. doi:10.1007/s00170-015-7338-1

10. Rappold E (2005) Schleifbrand im Griff. Werkstatt + Betrieb, Issue 9, pp 156-159. (in German)

11. Kopac J, Krajnik P (2006) High-performance grinding — a review. J Mater Process Technol 175:278-284. doi:10.1016/j.jmatprotec. 2005.04.010

12. Krajnik P, Kopac J (2005) Empirical modelling and optimisation of precision grinding. In: Kuljanic E (ed) AMST'05 advanced manufacturing systems and technology. Springer pp 201-210

13. Roquefeuil $\mathrm{F}$ (2003) Abral: a new approach to precision grinding. Abrasive Magazine Dec pp 24-29

14. Webster J, Tricard M (2004) Innovations in abrasive products for precision grinding. CIRP Ann Manuf Technol 53:597-617. doi:10. 1016/S0007-8506(07)60031-6
15. Sundararajan D (2001) The discrete fourier transform: theory, algorithms and applications. World Scientific Pub Co Inc

16. Bourlier F (2005) Abrasive particles based on aluminium oxynitride. US Patent Application Publication No. 2005/0160678 A1

17. Klocke F (2009) Manufacturing processes 2: grinding, honing, lapping. Springer

18. Alteo: Alteo fused alumina more than 100 years of expertise. http:// alteo-alumina.com/sites/default/files/Ressources/ALTEO\% 20Fused\%20Aluminas\%20Brochure 2.pdf. Accessed 25 Jan 2015

19. Cardarelli F (2008) Materials handbook. Springer

20. Smith SK (2002) Digital signal processing. A practical guide for engineers and scientists. Newnes. ISBN: 978-0750674447

21. Mitra SK (2001) Digital signal processing: a computer-based approach. McGraw-Hill Science/Engineering/Math, 2nd edition. ISBN-13: 978-0072513783

22. Stoica P, Moses R (2005) Spectral analysis of signals. Prentice Hall, Inc. Upper Saddle River, New Jersey. ISBN: 978-0131139565

23. Kuo SM, Lee BH, Tian W (2013) Real-time digital signal processing: fundamentals, implementations and applications. Wiley, 3rd edition. ISBN-13: 978-1118414323

24. Welch PD (1967) The use of fast fourier transform for the estimation of power spectra: a method based on time averaging over short, modified periodograms. IEEE Transactions on Audio Electroacoustics, AU-15 pp 70-73. doi: 10.1109/TAU.1967. 1161901

25. Krejcar O, Frischer R (2011) Non destructive defect detection by spectral density analysis. Sensors 11(3):2334-2346. doi:10.3390/ s110302334

26. Corinthios M (2009) Signals, systems, transforms, and digital signal processing with MATLAB. CRC Press. ISBN: 9781420090482

27. Boersma P (1993) Accurate short-term analysis of the fundamental frequency and the harmonics-to-noise ratio of a sampled sound. Proceedings of the Institute of Phonetic Sciences, Volume 17, Issue 1193, pages 97-110. URI: http:/www.cs. northwestern.edu/ pardo/courses/eecs352/papers/pitch tracking - boersma.pdf

28. Rabiner LR (1977) On the use of autocorrelation analysis for pitch detection. IEEE Trans Acoust Speech Signal Process 25(1):24-33. doi:10.1109/TASSP.1977.1162905

29. Vilhelm J, Rudajev V, Lokajiček T, Živor R (2008) Application of autocorrelation analysis for interpreting acoustic emission in rock. Int J Rock Mech Min Sci 45(7):1068-1081. doi:10.1016/j.ijrmms. 2007.11.004, ISSN: 1365-1609

30. Vaseghi SV (2006) Advanced digital signal processing and noise reduction. Wiley, 3rd edition. ISBN: 978-0-470-09495-2

31. Broersen PMT (2006) Automatic autocorrelation and spectral analysis. Springer-Verlag London Limited. ISBN: 978-1-84628-328-4

32. Hewlett Packard (2000) The fundamentals of signal analysis. Application note 243. Agilent Technologies. Hewlett Packard Intercontinental. URI: http://cp.literature.agilent.com/litweb/pdf/ 5952-8898E.pdf

33. Lee YW, Yuk Wing, Cheatham TP, Wiesner JB (1949) The application of correlation functions in the detection of small signals in noise. Technical report no. 141. Research Laboratory of Electronics, Massachusetts Institute of Technology. URI: http:// hdl.handle.net/1721.1/4912

34. Leis JW (2011) Digital signal processing using MATLAB for students and researchers. John Wiley \& Sons. ISBN: 978-0-47088091-3

35. Vetterli M, Kovacevic J, Goyal VK (2014) Foundations of signal processing. Cambridge University Press. ISBN: 978-1107038608

36. Martin GD (2005) Chirp Z-transform spectral zoom optimization with MATLAB. Sandia National Laboratories, 2005-7084, report printed Nov 
37. Rabiner LR (2004) The chirp z-transform algorithm - a lesson in serendipity. IEEE Signal Process Mag 21(2):118-119

38. Rabiner LR, Schafer RW, Rader CM (1969) The chirp z-transform algorithm. IEEE Trans Audio Electroacoust Vol. AU-17, No. 2, 8692, June

39. Needleman SB, Wunsch CD (1970) A general method applicable to the search for similarities in the amino acid sequence of two proteins. J Mol Biol 48(3):443-453. doi:10.1016/0022-2836(70) 90057-4
40. Chakraborty A, Bandyopadhyay S (2013) FOGSAA: Fast Optimal Global Sequence Alignment Algorithm. Sci Rep 3, 29 April. doi: 10.1038/srep01746

41. Nordström KJV, Sällman Almén M, Edstam MM, Fredriksson R, Schiöth HB (2011) Independent HHsearch, Needleman-Wunschbased, and motif analyses reveal the overall hierarchy for most of the G protein-coupled receptor families. Mol Biol Evol 28(9):24712480. doi:10.1093/molbev/msr061 